\title{
Design and construction of wood beams of Southern Xinjiang rural residents
}

\author{
Adil Mammat ${ }^{1, \text { a }}$ Minawar Ahmat ${ }^{2, b}$ \\ ${ }^{1}$ Xinjiang Vocational and Technical College of Construction, Urumqi, 830026 , China \\ ${ }^{2}$ Xinjiang Vocational and Technical College of Construction, Urumqi, 830026 , China \\ aemail: 1250698045@qq.com , bemail: 2909436281@qq.com
}

\begin{abstract}
Keywords: Brick Wood structure; Wooden beams; Sectional dimensions; Node ; Connection
Abstract: Brick Wood structured bungalow is the main form of Earthquake resistant housing structure in Xinjiang rural residents, Set certain structural measures for the wood and Brick structured bungalow can get a good seismic performance. Based on many years of experience in design and related specific information.This article is focuses on determine the method of Wooden beams, Sectional dimensions and section shape .The structural requirements of wooden beams connection, the notes about selecting wooden beams and provided reference for whom operating with design or built wood and brick structured houses.
\end{abstract}

\section{Introduction}

Brick wood structure refers to the vertical load-bearing walls, columns in houses with brick or stone used in masonry mortar, roof is built with wooden structure etc.. Because of its convenient for Space division, light weight, and a single material, Simple construction process and low cost; plus, brick wood houses less stiffness, better flexibility, toughness, long structure vibration period, good cope with vertical seismic force. Wood as a building material has the characteristics of light weight, high strength, beautiful appearance, good processing performance etc., so loved by the people since ancient times. Wooden roof has the "softness" feature, Through the allowable deformation and fault range of the structure consume the earthquake energy, so that we can ensure the overall safety of the structure. Brick Wood structured bungalow is the main form of Earthquake resistant housing construction in rural areas of Xinjiang, Set certain structural measures for the wood and Brick structured bungalow have a good seismic performance. This article is focuses on to determine the method of Wooden beams, Sectional dimensions and section shape, The structural requirements of wooden beams connection, the notes about selecting wooden beams and provided reference for whom operating with design or built wood and brick structured houses.

\section{Wooden beams (wood purlins) selection}

According to the datum about earthquake disaster indicated that damage of single-story house mainly occurs on the wall and roof system. Roof deformation and roof collapsed are more common damages of Roof system, the main reason is because of the beams and purlins are corrosive and they have poor connectivity between walls of the house, the connection structure is irrational, purlin beam have not enough rigidity and strength and so on, thus aggravates the damage of whole house. Wooden beams are the main supporting structure of roof load, so it is very important the selection of beam, cross-section design , and the node processing .

\section{The material of the wooden beams}

Houses in three states and prefectures of Southern Xinjiang were mainly built by using wood beams of Aspen trees. Aspen tree is a fast-growing, high-yield species, it has wide adaptability, growing season long, growing speedily and other characteristics. Southern and northern parts of Xinjiang have a wide range of Aspen trees that resources are relatively abundant. Xinjiang Aspen tree is very light, strength is high, good elasticity, and its fiber content is not only very long but also very high, processing is very convenient.

\section{Selection Requirements}


(1) The selected wood are required to be straight texture, less stutter, not decayed, peeled and drying, moisture content should be less than $12 \%$ in general.

(2) selected load bearing timbers are should be used new materials, not the old wood.

(3) selected wood should be done antiseptic treatment before using.

(4) the wooden beam should adopt the logs, logs and lumber in the visual material grade II a.

\section{Design the Wooden beams of Brick Wood structures}

\section{Residential roof}

Southern Xinjiang traditional houses generally flat roof bungalows. dense purlin on the Roof beam, reed mat or board on the dense purlin . Roof layout system is neat, simple structure, clear the characteristics of load transfer.

\section{Residential Roof procedure}

Common practice: (bottom-up) timber purlin spacing is $600 \mathrm{~mm}$; the rafters cross-sectional dimensions of $50 \mathrm{~mm} \times 50 \mathrm{~mm}$, pitch $100 \mathrm{~mm}$, covered with two layer reed mat, put straw for insulation, thickness $180 \mathrm{~mm}$ (making slope 2\%), three times with 100 thick grass mud, surface spray salt water and press polishing.

\section{The section forms of beam}

Section forms of beam with circular, square and rectangular. the houses that have ceiling try to use the forms of circular cross section, this can be without destroying to the log internal organization.

\section{Roof load value}

According to the relevant provisions of the Xinjiang Uygur Autonomous Region rural earthquake housing residential design selection constant load standard value of the roof should not exceed 3.5 $\mathrm{KN} / \mathrm{M} 2$ (plus ceiling load of $0.5 \mathrm{KN} / \mathrm{m} 2$ ), roof live load standard value is $0.5 \mathrm{KN} / \mathrm{M} 2$

\section{The Calculation of beam load}

standard value of Load $g_{k}=4 \mathrm{KN} / \mathrm{m}^{2}, \quad \mathrm{q}_{\mathrm{k}}=0.5 \mathrm{KN} / \mathrm{m}^{2}$

Constant load control $: \mathrm{p}_{\mathrm{n}}(\mathrm{g})=(1.35 \times 4+1.4 \times 0.7 \times 0.5)$

$$
=5.89 \mathrm{KN} / \mathrm{m}^{2}
$$

Live load control: $\mathrm{p}_{\mathrm{n}}(\mathrm{q})=(1.2 \times 4+1.4 \times 0.5)$

$$
=5.5 \mathrm{KN} / \mathrm{m}^{2}
$$

Design value of load: $P_{n}=\max \left\{P_{n}(g), P_{n}(q)\right\}$

$$
=5.89 \mathrm{KN} / \mathrm{m}^{2}
$$

The load design value in the wood purlin :

$$
\mathrm{P}=5.89 \times 0.6=3.53 \mathrm{KN} / \mathrm{m}
$$

\section{Determine the section size of wood purlin}

At the same time to meet the specification requirements:

(1)The flexural load - bearing capacity:

picture -1

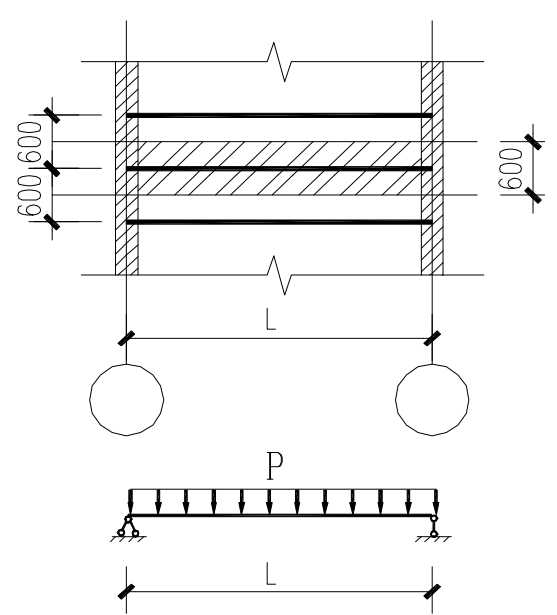

Sketch of beam calculation

$$
\sigma_{m}=\frac{M}{W_{n}} \leq f_{m}
$$

(2) Shear strength capacity:

$$
\tau=\frac{V S}{I b} \leq f_{V}
$$

(3) Requirements of deflection

$$
f=\frac{5 p l^{4}}{384 E I} \leq\left\{\begin{array}{l}
\frac{l}{250}(L>3.3 m) \\
\frac{l}{200}(L \leq 3.3 m)
\end{array}\right.
$$

(in formula $\mathrm{P}=3.53 \mathrm{KN} / \mathrm{m}, \mathrm{E}=9000 \times 0.9=8100 \mathrm{~N} / \mathrm{mm} 2, \mathrm{fm}=11 \mathrm{~N} / \mathrm{mm} 2, \mathrm{fv}=1.3 \times 0.9=1.17 \mathrm{~N} / \mathrm{mm} 2$ ) 
Through the calculation, the residence breadth timber purlin section dimension determination is shown in table 1 according to the requirements of deflection



Note: 1.In the Table the circular wood purlin diameter be determined bay small side diameter.

2.when doing rectangular beams by using circular log, it is most economic when the aspect ratio is 3:2.

\section{Wooden beam(timber purlin) connection types}

According to the different connection type and stress condition, there are many connection types. they are the Direct force transmission, indirect force transmission via connecting piece, common tooth connection, pin connection and connections types that connect by metal connecting piece.

\section{Step joins}

Step joins are end of the compression member make saw, cogging in another member, make tooth tenon directly against the bearing in alveolar, through the pressure-bearing of bearing surfaces of the bearing do force transmission. Therefore, the tooth connection can only be used to transfer the pressure, this is its characteristic. Tooth connection structure is simple, Clear load transfer, can make by using simple tools, because its structure is exposed, easy to check the construction quality and Working conditions. Both of bolt connection and screw connection can be used in double shear connection or single shear connection. The nail arrangement, can use Thiele, stagger arrangement or oblique - arranged etc..

\section{Pin Connection}

Common pins are made of steel or wood with the shape of round bar or schistose, are used for to prevent being connected component of the relative movement. In connection, pins are flexural, timber components are mainly being pressure-bearing. These two kinds of work have better plasticity, so the pin connection is a more reliable connection. Belongs to a round rod-shaped are bolts, nails, steel pins, screws, glass steel round pin etc; belongs to schistose are glass steel plate pin, steel plate pin etc.. The various pins, bolts and screws are widely used in wood structured buildings.

\section{The nodal point shapes of steel member connections}

When design of large wooden buildings if use the nodal point shapes of steel member connections, the span of the structure and component size is relatively large, traditional structure forms can not meet the structural requirement, design method of steel structure often being used more in structural design, By actively using metal components or steel structure connection model to meet the construction requirements of nodal point . Slight junction can be connected by using nails or bolts and other small steel components; In large structures timber component is frequently fixed with inserted steel plate in Glulam combination point, the connection between steel plate or connection between steel plate and concrete foundation can be connected by using bolts and other steel components. In the large span wood structures, the mentioned methods of rigid node designing can effectively solve the problem of node structure.

\section{Wooden beam (wood purlin) node design}

When design wooden roof system of earthquake zone, should be reinforced the connection between the structural member, structures and supports, especially it must be safe and reliable when connect two kind of stiffness widely different components. you can see Figure 2 the connection of wood 
purlin (WP) and wall, Figure 3.1 and 3.2 the connection of wooden beams (WB) and wooden pillar, Figure 4 the connection of wood purlin(WP)and wooden beams (WB).

\section{The considerations about wooden roof}

(1) Wooden roof construction should be operated by experienced carpenters and In accordance with the current norms requirements.

(2) The brick wood structured house load-bearing mainly by wood structure, so do not hang and put heavy weight on the house beams, and do not change its original dimension, stress direction.

(3) Wooden roof should use external drainage, if need to use internal drainage, should not use wooden roof gutters.

(4) Must be taken ventilation and moisture-proof measures to prevent the wood decay and insect.

(5) In order to prevent the occurrence of roof insulation "stuffy rot", should not be used organic materials as insulation layer., Not suitable to use the roof panel or iron sheet, When need to use Is is recommend to use asbestos tile as a waterproof material.

(6) The indoor use wooden materials should be treated with a preservative, should not be irritating odor; if the wood need to be painted, paint not to have effect on wood.

(7) When design wood constructions in windy areas, effective measures should be taken to strengthen the ability of wind resistance of roof. To reduce the height and span of the skylight as far as possible.

(8) The steel part of the wooden structure, should be taken anti - rust measures.

(9) After the house is built, make an inspection and maintenance on wood structure.

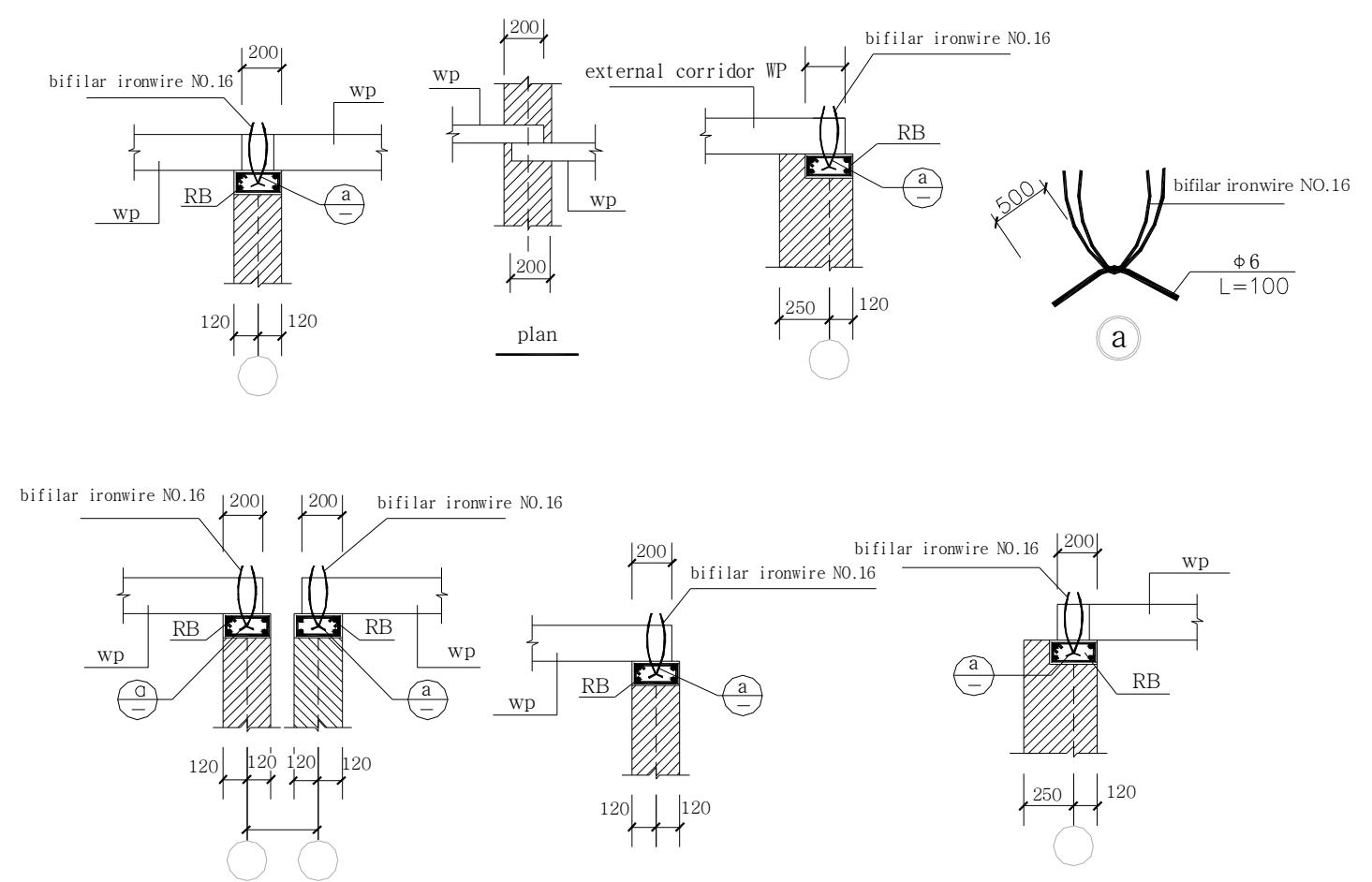

Figure 2 the connection of wood purlin (WP)and wall 

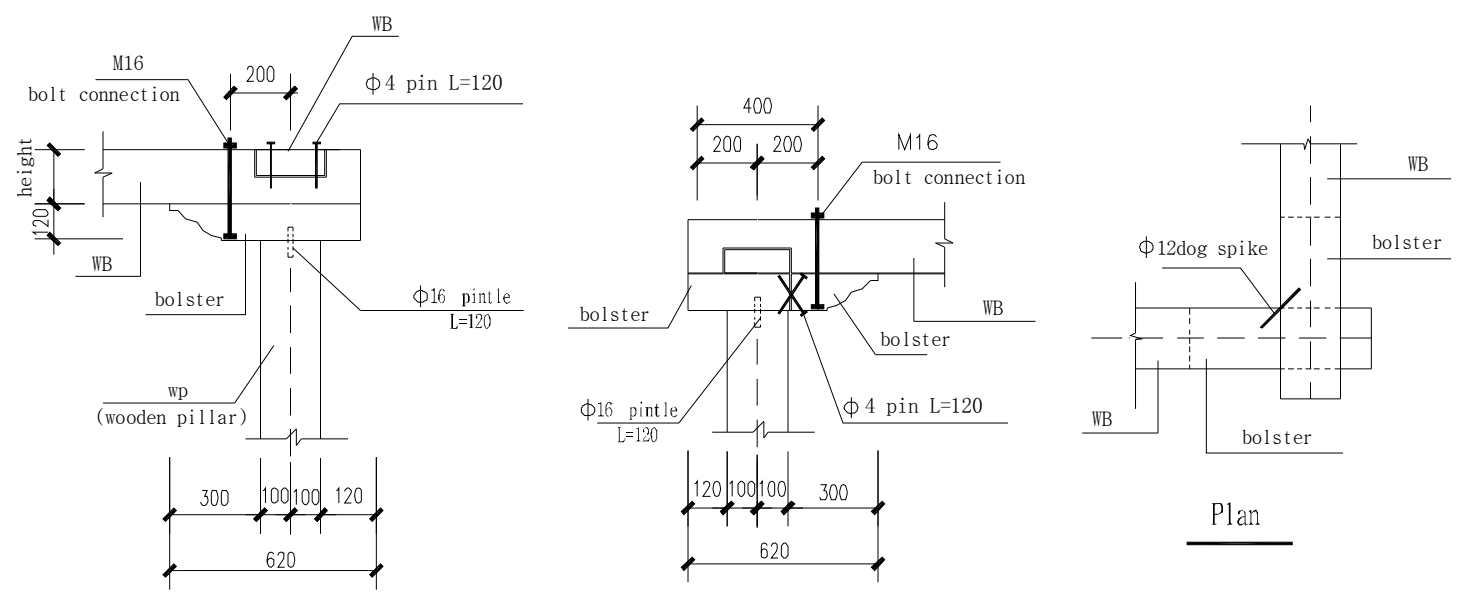

Figure 3.1 the connection of wooden beams (WB) and wooden pillar


Figure 3.2 the connection of wooden beams (WB) and wooden pillar Figure 4 the connection of wood purlin (WP)and wooden beams (WB)

\section{Conclusion}

In recent years, Xinjiang vigorously promote to built rural houses and indemnificatory housing project, and has taken remarkable results. Brick Wood structured bungalow is the main form of Earthquake resistant housing structure in rural residents, Wooden beams are the main supporting structure of roof load, so the selection of beam, the design of section form and nodal point treatment Should be chosen according to structural measures of Anti-seismic. It has important realistic significance and practical value for the brick wood structure houses construction in rural places of Southern Xinjiang .

\section{References}

[1] GB/T 50772-2012, The construction specification of wood structure engineering Press.2012 .

[2] GB 50005-2003 The design specifications of wood structure engineering Press.2005.

[3] GB 50206-2002 The specification of wood structure engineering construction quality acceptance Press.2002.

[4] 04G604-2003 The new atlas of Building Anti seismic structure in villages and small towns Press.2005.

[5] Xinjiang Uygur Autonomous Region Rurale Anti-seismic housing office, Xinjiang Uygur Autonomous Region Rural residents Anti-seismic housing design selections, Urumqi:Xinjiang Uygur Autonomous Region construction standards Service center Press.2005. 